\title{
Underweight May Be a Risk Factor for Lower Bone Density in Chronic Hepatitis C Infected Male Patients
}

\author{
Amin R. Soliman, Hatem Darwish, Ahmed Hamdy*, Mahmoud A. Soliman \\ Internal Medicine Department, Faculty of Medicine, Cairo University, Cairo, Egypt \\ Email address: \\ Aroshdy@hotmail.com (A. R. Soliman), hatem_darwish@hotmail.com (H. Darwish), Ahramadan777@gmail.com (A. Hamdy), \\ Aahamdy777@gmail.com (M. A. Soliman)
}

\section{To cite this article:}

Amin R. Soliman, Hatem Darwish, Ahmed Hamdy, Mahmoud A. Soliman. Underweight May Be a Risk Factor for Lower Bone Density in Chronic Hepatitis C Infected Male Patients. American Journal of Internal Medicine. Vol. 3, No. 5, 2015, pp. 213-216.

doi: $10.11648 /$ j.ajim. 20150305.14

\begin{abstract}
Background/Aim of the study: Osteoporosis and osteopenia are well known complications in patients with chronic liver disease, we aimed to investigate Egyptian male patients with chronic hepatitis $\mathrm{C}$ infection as regard the bone mineral density and risk factors for osteoporosis in this subpopulation and correlating it to BMI (body mass index). Patients and methods: One Hundred ninety-three Egyptian male patients with hepatitis C virus CLD has been enrolled and consented: 116 under weight and 77 normal weight, Chronic HCV infection was confirmed by positive anti-HCV antibodies and HCV RNA PCR. Cirrhosis was diagnosed based on sonographic and laboratory criteria. Noninvasive methods were used: the FibroScan test was used for assessment of liver fibrosis. Blood was drawn for routine tests included total serum calcium, phosphate, creatinine and total alkaline phosphatase using standard methods. 25-hydroxy vitamin D (25OHD) were done. Bone mineral density: BMD of the lumbar spine, femoral neck: using dual energy x-ray absorptiometry (DEXA)Scan were analyzed by the same technician. Results were correlated to Body mass index and Serum vitamin D level. Results: Demographic Data and Clinical Characteristics of Under and Normal Weight Chronic Hepatitis C Men were recorded, the results showed statistically significant correlations between under and normal weight HCV patients regarding BMI and BMD (in right hip and femoral neck, $\mathrm{p}$ values were 0.002 and 0.004 , respectively). Subnormal 25 hydroxy vitamin D levels were present in $64 \%$ of the underweight patients and $51 \%$ of the normal weight patients with no significant differences between both groups. Conclusion: the body weight and BMI might be more detrimental for low BMD in male patients with CLD secondary to HCV infection rather than vitamin D status.
\end{abstract}

Keywords: Chronic Hepatitis C, Low Vitamin D Level, Underweight, Bone Mineral Density

\section{Introduction}

Hepatitis $\mathrm{C}$ is a global health problem caused by infection with the hepatitis $\mathrm{C}$ virus ( $\mathrm{HCV}$ ); it is estimated that as many as 170 million persons worldwide may be infected with $\mathrm{HCV}$ and is the single important cause of liver disease in Egypt [1].

The late complications of chronic HCV infection result in serious public-health consequences, such as chronic hepatitis, cirrhosis, and hepatocellular carcinoma[2].

Chronic hepatitis $\mathrm{C}$ (due to $\mathrm{HCV}$ ) is a systemic disease rather than hepatotropic virus infection, and is associated with a number of extra hepatic manifestations. Osteoporosis and osteopenia are well known complications in patients with chronic liver disease. Its prevalence varies considerably. The international incidence of bone disease is reported to vary from 11 to $48 \%$ in patients with chronic liver disease
(CLD)[3].

This wide range is attributed to many factors including patient selection, diagnostic criteria, underlying liver disease and it also increases with the increased severity of the liver disease defined as advanced Child-Pugh score [4]. Osteoporosis is progressive systemic skeletal disease characterized by low bone mass and micro architectural deterioration of bone tissue, with a consequent increase in bone fragility and susceptibility to fracture. Common fractures are vertebral compression fractures, fractures of the distal radius, and proximal femur [5].

Although best characterized in chronic cholestatic liver disease, osteopenic bone disease and fracturing are well-recognized complications of cirrhosis [6].

The relationship between osteopenic bone disease and non-cholestatic liver disease is less well defined. Recent reports suggest its possible relationship with viral hepatitis $B$ 
and C infection [7].

The aim of our current study was to investigate Egyptian male patients with chronic hepatitis $\mathrm{C}$ infection as regard the bone mineral density and risk factors for osteoporosis in this subpopulation.

\section{Patients and Methods}

Cross-sectional study with time span for inclusion set at 5 years.

We enrolled 193 Egyptian male patients with hepatitis C virus Chronic liver disease: 116 under weight patients (with BMI less than $18.5 \mathrm{~kg} / \mathrm{m}^{2}$ ) and 77 normal weight patients ( with BMI 18.5-24.5 $\mathrm{kg} / \mathrm{m}^{2}$ ) infected with $\mathrm{HCV}$ who presented between March 2006 and February 2011 at Cairo University Hospitals outpatient clinics. Chronic HCV infection was confirmed by positive anti-HCV antibodies and HCV RNA. Cirrhosis was diagnosed based on sonographic and laboratory criteria or liver biopsy results Noninvasive methods used were: the FibroScan result (with an elasticity value $>12.5 \mathrm{kPa}$ ) in priority and the result of FibroTest. Protocol has been approved by research ethical committee and all patients provided informed consent.

\section{Exclusion Criteria:}

Decompensated liver cirrhosis (Ascitis, Encephalopathy, esophageal or gastric varices ), Fibroscan results : F score more than F2, hepato-cellular carcinoma and other associated causes of chronic liver disease (Hepatitis B virus, Autoimmune hepatitis and any history of Drug induced liver diseases), patients on steroids or any other drug induced osteopenia or osteoporosis, hyperthyroidism, Chronic kidney disease, associated hypogonadism and any congenital or collagen disorders with associated low bone density.

Patients' medical records and patient interviewed for gathering epidemiological, Clinical and Biological data. Blood was drawn in the morning after an overnight fasting. Routine tests included total serum calcium, phosphate, and creatinine and total alkaline phosphatase using standard methods. 25-hydroxy vitamin D (25OHD) (radioimmunoassay technique, DiaSorin, Stillwater, MN, USA). Bone mineral density: BMD of the lumbar spine, femoral neck: using dual energy $x$-ray absorptiometry (DEXA; Hologic, Bedford, CT). Scans were analyzed by the same technician. Results correlated to: Body mass index and Serum vitamin D.

\section{Statistical Analysis}

Results were compared with normative curves and expressed as T-score and Z-score. WHO diagnosis classification was used to categorize bone status as normal if the T-score was $>-1$, osteopenia if the T-score was between -1 and -2.5 , and osteoporosis if the T-score was $<-2.5$. Because bone abnormalities affected rather young $\mathrm{HCV}$-infected patients, the Z-scores were used to compare patients' BMD with the average value for a person of the same age and gender. Z-score $<-2.0$ was used to characterize $\mathrm{HCV}$-infected patients having less bone mass than expected.

Statistical analyses: SAS software (SAS Institute Inc, Cary, NC). Comparative analysis: Kruskal-Wallis test for median values and their interquartile ranges (IQR) if continuous data; $\chi 2$ test was used to analyze the differences in categorical data. Statistical significance was set with a $\mathrm{P}$ value $<0.05$. Univariable regression (stepwise forward) was performed to identify variables predictive of osteopenia and osteoporosis. All variables with a $\mathrm{P}$ value $<0.25$ were included in a multivariable logistic regression model to examine the potential determinants of osteopenia or osteoporosis.

\section{Results}

Demographic and clinical characteristics were compatible and showed no statistically significant difference between underweight and normal weight, however $\mathrm{m}$ there was a statistically significant difference between both groups regarding BMI and body weight $(p<0.001)$ (Table 1$)$.

Table 1. Demographic Data and Clinical Characteristics of Under and Normal Weight Chronic Hepatitis C Men.

\begin{tabular}{llll}
\hline Parameter & $\begin{array}{l}\text { Underweight } \\
\text { N= 116 }\end{array}$ & $\begin{array}{l}\text { Normal } \\
\text { weight } \\
\text { N=77 }\end{array}$ & $\begin{array}{l}\boldsymbol{P} \\
\text { value }\end{array}$ \\
\hline $\begin{array}{l}\text { Age (years) } \\
\text { Weight (kg) }\end{array}$ & $\begin{array}{l}38.5 \pm 9.8 \\
63.2 \pm 10.4\end{array}$ & $\begin{array}{l}39.7 \pm 10.3 \\
74.5 \pm 12.1\end{array}$ & 0.85 \\
$\begin{array}{l}\text { Body mass index (kg/m2) } \\
\text { Smoking, n (\%) }\end{array}$ & $\begin{array}{l}15.6 \pm 3.70 \\
41(35)\end{array}$ & $21.7 \pm 3.50$ & 0.001 \\
$\begin{array}{l}\text { Lifetime tobacco exposure } \\
\text { (pack.year) }\end{array}$ & $29.00 \pm 8$ & $30.00 \pm 7$ & 0.90 \\
$\begin{array}{l}\text { Physical activity } \\
\text { (3x/week/20 min), n(\%) }\end{array}$ & $28(24)$ & $18(23)$ & 0.82 \\
$\begin{array}{l}\text { Previous prolonged } \\
\text { immobilization, n (\%) }\end{array}$ & $26(22.4)$ & $15(19.4)$ & 0.80 \\
$\begin{array}{l}\text { Family history of } \\
\text { osteoporosis, } \mathrm{n}(\%)\end{array}$ & $24(20.1)$ & $16(20.6)$ & 0.80 \\
$\begin{array}{l}\text { Family history of femur } \\
\text { fracture, n(\%) }\end{array}$ & $12(10.3)$ & $10(13)$ & 0.30 \\
\hline
\end{tabular}

$\mathrm{p}$ value $<0.05$ is significant

No significant differences between BOTH GROUPS as regards liver functions and HCV viremia level (Table 2).

Table 2. Biochemical Bone Markers and Laboratory Tests of Bone and Mineral Metabolism in Under and Normal Weight HCV Patients.

\begin{tabular}{llll}
\hline Parameter & $\begin{array}{l}\text { Underweight } \\
\text { N= 116 }\end{array}$ & $\begin{array}{l}\text { Normal weight } \\
\mathbf{N}=\mathbf{7 7}\end{array}$ & P value \\
\hline Albumin (g/dl) & $3.41 \pm 0.33$ & $3.52 \pm 0.24$ & 0.40 \\
Alanine transferase (u/l) & $76.5 \pm 66.7$ & $80.5 \pm 60.0$ & 0.32 \\
Aspartase transferase (u/l) & $80.3 \pm 65.5$ & $78.7 \pm 70.7$ & 0.45 \\
HCV -RNA viral titre & $1,850,000 \pm$ & $1.790,000 \pm$ & 0.10 \\
HDL (mg/dl) & 965,000 & $1,059,000$ & 0.20 \\
\hline
\end{tabular}

There was statistically significant difference regarding BMD (detected by DEXA) between both groups in both right hip and right femoral neck but results were non-significant regarding lumbar spine (L1-L4), and after ADJUSTMENT for Weight, BMI, HDL and ALT it was also significant when 
BMD is measured in the right hip. (Table $3 \& 4$ ).

Table 3. BMD in Under and Normal Weight HCV Patients.

\begin{tabular}{llll}
\hline BMD & $\begin{array}{l}\text { Under weight } \\
\mathbf{N = 1 1 6}\end{array}$ & $\begin{array}{l}\text { Normal weight } \\
\mathbf{N}=\mathbf{7 7}\end{array}$ & P value \\
\hline Right hip & $0.852 \pm 0.117$ & $0.930 \pm 0.123$ & 0.002 \\
Femoral neck & $0.736 \pm 0.119$ & $0.812 \pm 0.132$ & 0.004 \\
Spine (11-14) & $1.136 \pm 0.12$ & $1.153 \pm 0.13$ & 0.86 \\
\hline
\end{tabular}

Table 4. BMD in under and Normal weight HCV patients AFTER ADJUSTMENT for Weight, BMI, HDL and ALT.

\begin{tabular}{llll}
\hline BMD & Under weight & Normal weight & P value \\
\hline RIGHT HIP & $0.725 \pm 0.141$ & $0.805 \pm 0.145$ & 0.002 \\
\hline
\end{tabular}

Subnormal 25 hydroxy vitamin D levels were present in $64 \%$ of the underweight patients and $51 \%$ of the normal-weight patients (Table 5).

Table 5. Classification of $25 \mathrm{H}$ Vitamin D Status in Under and Normal HCV patients.

\begin{tabular}{lll}
\hline & $\begin{array}{l}\text { Underweight } \\
\mathbf{N}=\mathbf{1 1 6}\end{array}$ & $\begin{array}{l}\text { Normal weight } \\
\mathbf{N}=\mathbf{7 7}\end{array}$ \\
\hline Sufficiency $(>30) \mathrm{n}(\%)$ & $42(36)$ & $38(49)$ \\
Insufficiency $(11-29) \mathrm{n}(\%)$ & $68(59)$ & $36(46)$ \\
Deficiency $(<10) \mathrm{n}(\%)$ & $6(5)$ & $3(5)$ \\
\hline
\end{tabular}

\section{Discussion}

The incidence of osteoporosis in chronic liver diseases varies widely, depending on the patient population and the underlying liver disease and its severity [8]. In addition to severe cholestatic liver disease, significant osteoporosis is generally reported in patients with cirrhosis, especially secondary to hepatitis C [9]. The amount of bone loss during lifetime is determined by sex, age, body mass index (BMI), nutrition (e.g. the amount of dairy, salt, and protein), alcohol consumption, smoking, physical activity, some medications, and some diseases such as cirrhosis [10].

In our current study we tried to explore this issue in male Egyptian patients with chronic hepatitis $\mathrm{C}$ infection and advanced cirrhosis. We choose male patients to excluding confounding factors affecting BMD in females.

Our results showed significant association of low BMD and underweight. With specific regard to mechanical-loading factors, the skeleton likely responds to mechanical stress such as body weight with a stimulation of osteoblast activity. This is one reason suggested for why obese women experience a lower risk of developing an osteoporotic fracture compared with females who are closer to their desirable body weight. Prolonged immobilization directly leads to bone and muscle losses at weight-bearing skeletal sites $[11,12]$.

Increased fat mass likely supports greater estrogen production from androgens. Greater body weights also are associated with greater serum concentrations of testosterone, dehydroepiandrosterone-sulfate, and androstenedione. Together, these hormones contribute to bone maintenance $[13,14]$. Increased fat mass also provides a cushion against bone trauma in a fall, especially in the hip region in elderly women. Researchers have even advocated padding for the hip region in thin elderly women to make up for the loss of fat protection [15]. Underweight and poor appetite in such high risk group leads to inadequate intake of nutrients associated with bone health, such as calcium. Weight loss has been shown to be a factor associated with low BMD in perimenopausal women. Thus, maintenance of a high BMI throughout life likely contributes to a greater nutrient intake and in turn to maintenance of BMD [16].

How much body weight is needed to confer a reduced risk of osteoporosis is an open question. Generally, a BMI around 30 is associated with a $4-8 \%$ greater lumbar spine BMD, $8-9 \%$ greater hip region $\mathrm{BMD}$, and $25 \%$ greater radius $\mathrm{BMD}$ compared with a BMI of around 20. A BMI of 30 is also associated with one-half the loss in lumbar spine BMD in the early postmenopausal years compared with a BMI of 20 . Studies showed that cases of vertebral fractures between otherwise-matched subjects were more likely seen in subjects with a BMI $<24$ than in subjects with a BMI $>26$ [17].

Interestingly, the lower BMD was noted at the hip and femur neck not at the spine. Discordance in diagnosis of osteoporosis is defined as the presence of different categories of T-scores (osteoporosis, osteopenia, and normal) in 2 skeletal sites of an individual patient. This phenomenon has been divided into 2 groups: major and minor. Minor discordance happens when the different diagnostic classes are adjacent, ie, patient is diagnosed as osteoporotic in 1 site and osteopenic in the other site, or, osteopenic in 1 site and normal in the other site. If the diagnosis is osteoporosis in 1 site and the other site is in the normal range, the discordance falls into the major class [18]. In our study, T-score of hip and spine were in the same class but only significant difference was in BMD at the hip only. This difference might explained by that our patients are all ascetic which put more weight and stress on lumbar spine which is known to stimulate bone formation.

Recently, the role of vitamin D in CLD has received much attention, given its inherent activation process by the liver and the high prevalence of vitamin D deficiency in this patient group [19]. In present study, serum levels of $25(\mathrm{OH})$ vitamin $\mathrm{D}$ in patients with chronic liver disease were decreased and this level would be reduced more with the progression of cirrhosis. It seems that both reduced exposure to UV light and dietary insufficiency account for vitamin D deficiency in the majority of cases. There is also impaired cutaneous synthesis of vitamin D in the presence of jaundice [20]. There was no statistically significant difference between both groups as regard other risk factors for low BMD, e.g. age, smoking, exercise/immobility and viral load.

As vitamin D insufficiency is associated with secondary hyperparathyroidism, increased bone turnover, and accelerated bone loss, administration of vitamin D supplementation seems to be a reasonable approach in these patients. Conflicting findings in observational studies exist with regard to correlations between vitamin $\mathrm{D}$ status and measurements of bone mineral density (BMD) in CLD patients. For instance, Chen et al. found a significant correlation between lumbar spine BMD and 25(OH)D levels 
in patients with cirrhosis compared with controls [21]. Moreover, both serum 25(OH)D and $1,25(\mathrm{OH}) 2 \mathrm{D}$ concentrations were considered to be strong independent predictors of hip bone density in patients with cirrhosis [22]. Conversely, others have failed to find evidence to support such correlations [23]. Recently, vitamin D deficiency has been linked to a low rate of sustained virological response (SVR) in $\mathrm{HCV}$ patients undergoing interferon-based therapy, and to more severe liver fibrosis [24,25]. Conversely, some studies suggest that vitamin D supplements might improve treatment response in patients with chronic hepatitis $\mathrm{C}$ and increase the incidence of achieving SVR [26].

In conclusion, our study showed that vitamin D insufficiency and deficiency were prevalent in both studied groups under and normal weight (64 and $51 \%$ respectively) with no significant difference between the two groups. These results may lead us to conclude that the body weight and BMI might be more detrimental for low BMD in male patients with CLD secondary to $\mathrm{HCV}$ infection rather than vitamin $\mathrm{D}$ status

\section{Acknowledgement}

The authors declare they did not omit anyone who met the criteria of acknowledgement, and they performed every part of this study by themselves and no funds from any source were received for this work.

\section{References}

[1] Habib M, Mohamed M, Abdel-Aziz F, Magder L, Abdel-Hamid $\mathrm{M}$, Gamil F, et al. Hepatitis $\mathrm{C}$ virus infection in a community in the Nile Delta: risk factors for seropositivity. Hepatology 2001; 33(1): 248 .

[2] WHO Global surveillance and control of hepatitis C. Report of a WHO Consultation organized in collaboration with the Viral Hepatitis Prevention Board, Antwerp, Belgium. J Viral Hepat 1999; 6:35-47

[3] Lin J, Hsieh T, Wu C, Chen P, Chueh T, Chang W, et al. Association between chronic hepatitis $\mathrm{C}$ virus infection and bone mineral density. Calcif Tissue Int. Dec 2012; 91(6):423-429.

[4] Hay JE, Guichelaar MM. Evaluation and management of osteoporosis in liver disease. Clin Liver Dis 2005; 9: 747-66.

[5] Rachner T, Khosla S, Hofbauer L. Osteoporosis: now and the future. The Lancet. 2001; 377(9773): 1276-1287.

[6] Yousfi MM, Balan V, Douglas DD, Harrison ME, Mulligan DC, Moss AA, et al. End-stage liver disease secondary to hepatitis C infection and alcohol is a risk factor for osteoporosis [abstract]. Hepatology 2001;34:A232.

[7] McCullough AJ, O'Connor JF. Alcoholic liver disease: Proposed recommendations for the American College of Gastroenterology. Am J Gastroenterol 1998;93:2022-2036.

[8] Hay JE, Guichelaar MM Evaluation and management of osteoporosis in liver disease. Clin Liver Dis 2005; 9:747-766.

[9] Leslie WD, Bernstein CN, Leboff MS AGA technical review on osteoporosis in hepatic disorders. Gastroenterology 2003; 125:941-966.
[10] Luxon BA. Bone disorders in chronic liver diseases Curr Gastroenterol Rep 2011, 13 (1):40-8. Guanabens N, Pares A. Liver and bone Arch Biochem Biophys 2010, 503(1): 84-94.

[11] Frost HM. The pathomechanics of osteoporoses. Clin Orthop 1995; 200:198-225.

[12] Slemenda CW, Hui SL, Longcope C, Wellman H, Johnston CC. Predictors of bone mass in penmenopausal women. Ann Intern Med 1990;1 12:96-101

[13] Ribot C, Tremollieres F, Pouilles JM, Bonneu M, Germain F, Louvet JP. Obesity and postmenopausal bone loss: the influence of obesity on vertebral density and bone turnover in postmenopausal women. Bone 1988;8:327-31.

[14] Shiraki M, Ito H, Fujimaki H, Higuchi T. Relation between body size and bone mineral density with special reference to sex hormones and calcium regulating hormones in elderly females. Endocrinol 1pm 1991;38:343-9.

[15] Greenspan SL, Myers ER, Maitland LA, Resnick NM, Hayes WC. Fall severity and bone mineral density as risk factors for hip fracture in ambulatory elderly. JAMA 1994; 271:128-33.

[16] Holbrook U, Barrett-Connor E. The association of lifetime weight and weight control patterns with bone mineral density in an adult community. Bone Miner 1993; 20:141-9.

[17] Rico H, Revilla M, Villa LF, Hernandez ER, Fernandez JP. Crush fracture syndrome in senile osteoporosis: a nutritional consequence? J Bone Miner Res 1992;7:317-9.

[18] Woodson G. Dual X-ray absorptiometry T-score concordance and discordance between the hip and spine measurement sites. J Clin Densitom 2000;3:319-24.

[19] Arteh J, Narra S, Nair S. Prevalence of vitamin D deficiency in chronic liver disease. Dig Dis Sci 2010; 55: 2624-8.

[20] Teneva BH. Pathogenesis and assessment of renal function in patients with liver cirrhosis. Folia Med (Plovdiv) 2012;54 (4):5-13.

[21] Chen CC, Wang SS, Jeng FS, Lee SD. Metabolic bone disease of liver cirrhosis: Is it parallel to the clinical severity of cirrhosis? J Gastroenterol Hepatol 1996; 11: 417-21.

[22] Crawford BAL, Kam C, Donaghy AJ, Mccaughan GW. The heterogeneity of bone disease in cirrhosis: A multivariate analysis. Osteoporos Int 2003; 14: 987-94.

[23] Menon KV, Angulo P, Weston S, Dickson ER, Lindor KD. Bone disease in primary biliary cirrhosis: independent indicators and rate of progression. J Hepatol 2001; 35: 316-23.

[24] Petta S, Camma C, Scazzone C, et al. Low vitamin D serum level is related to severe fibrosis and low responsiveness to interferon-based therapy in genotype 1 chronic hepatitis C. Hepatology 2010; 51: 1158-67.

[25] Bitetto D, Fattovich G, Fabris C, et al. Complementary role of vitamin D deficiency and the interleukin-28B rs12979860 C/T polymorphism in predicting antiviral response in chronic hepatitis C. Hepatology 2011; 53: 1118-26.

[26] Bitetto D, Fabris C, Fornasiere E, et al. Vitamin D supplementation improves response to antiviral treatment for recurrent hepatitis C. Transpl Int 2011; 24: 43-50. 